\title{
Resíduos de peixe do Mercado de Ferro, Complexo do Ver-o-Peso, Belém, Pará
}

\section{Waste in the Fish Iron Market, Ver-o-Peso Complex, Belém, Pará}

\author{
Evelyn Rafaelle de Oliveira Souza $\oplus^{1}$, Bruno Pedroso da Silva $\oplus^{2}$, Otávio do Canto $\oplus^{3}$, Altem Nascimento \\ Pontes ${ }^{4}$
}

${ }^{1}$ Mestre em Ecologia Aquática e Pesca. Instituto Federal de Educação, Ciência e Tecnologia do Pará, Belém, Pará, +559198359-3561, evelynrafaelle@yahoo.com.br; ${ }^{2}$ Graduado em Biomedicina, Instituto Federal de Educação, Ciência e Tecnologia do Pará, Belém, Pará, b.brunob@hotmail.com; ${ }^{3}$ Doutor em Desenvolvimento Rural, Professor Titular da Universidade Federal do Pará, Professor Permanente do Programa de Pós-Graduação em Gestão dos Recursos Naturais e Desenvolvimento Local na Amazônia do Núcleo de Meio Ambiente, Belém, Pará, docanto@ufpa.br; ${ }^{4}$ Doutor em Ciências Físicas, Professor e Pesquisador do Programa de Pós-Graduação em Ciências Ambientais da Universidade do Estado do Pará, Belém, Pará, altempontes@ hotmail.com.

\section{A R T I G O}

Recebido: $20 / 06 / 2019$

Aprovado: 02/09/2019

\section{Palavras-chave:}

Pesca

Desperdício

Destinação

Key words:

Fishing

Waste

Destination

\section{R E S U M O}

O Complexo do Ver-o-Peso localiza-se na cidade de Belém, Pará, considerado a maior feira livre da América Latina, nele está incluso o Mercado de Ferro, responsável por comercialização de pescados, realizando filetagem e outros tipos de cortes que geram resíduos. O objetivo deste trabalho foi realizar um levantamento da geração e destinação dos resíduos de peixes gerados no Mercado de Ferro na cidade de Belém, Pará. A coleta de dados foi realizada nos anos de 2015 e 2018, com informações referentes aos resíduos de peixes por meio de formulários aos vendedores do interior do mercado; além de separação e pesagens dos resíduos de peixe em tipo 1 a pele; tipo 2 a carcaça e tipo 3, outros, que engloba nadadeiras, escamas, brânquias, e grude. No ano de 2018 obteve-se $1.845,65 \mathrm{~kg}$ de resíduos de peixes em um único dia, sedo a carcaça de peixe, a categoria de resíduo mais recorrente. As demais categorias apresentaram-se baixas e não foram encontrados intestinos, pois os peixes costumam ser eviscerados ainda na embarcação. A maioria dos comerciantes produzem $50 \mathrm{~kg}$ ou mais de resíduos diariamente por boxe, sendo a maior parte desses resíduos com destino ao aterro sanitário. A maioria dos comerciantes apresentaram conhecimentos referentes ao uso de resíduos de peixes para a produção de adubo, ração e para a alimentação humana. No Mercado de Ferro do Complexo do Ver-o-Peso, os resíduos mais frequentes são a carcaça, e a quantificação desses resíduos atinge um total superior a uma tonelada e meia por dia.

\section{A B S T R A C T}

Ver-o-Peso Complex is located in the city of Belém, Pará, and is considered the largest free market in Latin America. The Fish Iron Market is part of this complex, and is where fish is marketed, filleting is processed, and other types of cuts occur, which generate waste. The aim of this study was to conduct a survey on the generation and disposal of fish waste generated in the Fish Iron Market of Ver-o-Peso Complex. Data were collected in 2015 and 2018, and information on fish waste was obtained by applying forms with market vendors. Additionally, fish waste was sorted and weighed, and divided in type 1 (skin), type 2 (carcass), and type 3 (others), the latter encompassing other types of waste. In $2018,1,845.65 \mathrm{~kg}$ of fish waste was generated in one single day, and fish carcass was the most recurring waste category. The other categories were low and were not found in the intestines, as fish is usually eviscerated while still on board the vessel. Most merchants produce $50 \mathrm{~kg}$ or more of waste per box daily, and most of this waste is disposed in landfills. The majority of merchants who produced the waste from which the sample was collected were familiar with the use of fish waste in the production of fertilizers, animal feed, and human food. The most frequent waste item in the Fish Iron Market of Ver-o-Peso Complex is carcass, and the quantification of this waste reaches a total value higher than one ton per day.

\author{
Revista Verde \\ ISSN 1981-8203 \\ Pombal, Paraíba, Brasil
}

v. 14, n.4, out.-dez, p.562-570, 2019

doi: 10.18378/rvads.v14i4.6687 


\section{INTRODUÇÃO}

A nível global são gerados cerca de 1,3 bilhão de toneladas de resíduos sólidos por ano, com estimativas de aumento para 2,2 bilhões de toneladas até 2025, sendo que os países de baixa renda apresentarão as taxas que mais aumentarão nos próximos anos (HOORNWEG et al., 2012). De acordo com a Organização das Nações Unidas para a Alimentação e a Agricultura (FAO), 171 milhões de toneladas de pescados foram produzidos a nível mundial no ano de 2016, incluindo pesca extrativa e aquicultura (FAO, 2018). Desse total, 35\% das capturas foram desperdiçadas, e um quarto das perdas consistem em devoluções dos peixes mortos ao ambiente aquático, pelo fato de estarem abaixo do tamanho comercial ou fazerem parte da fauna acompanhante.

No Brasil, existe a Política Nacional de Resíduos Sólidos (PNRS), Lei $\mathrm{n}^{\mathbf{o}}$ 12.305, de 2 de agosto de 2010, que apresenta como um de seus princípios: "O reconhecimento do resíduo sólido reutilizável e reciclável como um bem econômico e de valor social, gerador de trabalho e renda e promotor de cidadania" (BRASIL, 2010). O Art. 9 da PNRS afirma que a prioridade é a não geração de resíduos, porém, caso haja geração de resíduos a ordem de prioridades na gestão e gerenciamento de resíduos sólidos será: redução, reutilização, reciclagem, tratamento dos resíduos sólidos e disposição final ambientalmente adequada dos rejeitos.

Estima-se que o estado do Pará possui $40 \%$ da produção de pescado desperdiçada, por falta de infraestrutura nos locais de captura e recepção, ocorrendo desperdício também durante o beneficiamento e comercialização do pescado (BRASIL, 2014). Segundo Silva et al. (2013), o estado do Pará foi o segundo maior produtor de pescado no ano de 2010, estando atrás de Santa Catarina, sendo ambos responsáveis por grande parte do aumento da produção pesqueira do Brasil.

Na cidade de Belém, existe o Complexo do Ver-o-Peso, considerado a maior feira livre da América Latina (CRUZ et al., 2015). O Complexo inclui duas feiras (Feira do Açaí e Feira do Ver-o-Peso); uma doca de embarcações (Doca do Ver-o-Peso, popularmente conhecida como "pedra"); dois mercados: Mercado de Ferro (ou de Peixe) e Mercado Francisco Bolonha (ou de Carne); duas praças (Praça do Pescador e Praça do Relógio) e o Solar da Beira (IPHAN, 2018).

O Complexo do Ver-o-Peso é administrado conjuntamente pela Secretaria Municipal de Meio Ambiente (SEMMA); Secretaria Municipal de Saúde (SESMA); Secretaria Municipal de Urbanismo (SEURB) e Secretaria Municipal de Economia (SECON) (SOUSA et al., 2017). O porto público do Complexo do Ver-o-Peso é considerado um dos principais locais de desembarque pesqueiro da Amazônia, com estimativa de desembarque médio diário em torno de 27 toneladas, entre os anos de 1993 a 1997 (BARTHEM, 2004).

O Mercado de Peixe, como é popularmente conhecido, foi inaugurado em 1901, consolidando-se como ponto de venda de produtos alimentícios da Amazônia, e foi tombado pelo Instituto do Patrimônio Histórico e Artístico Nacional (IPHAN), em 1977 (CRUZ et al., 2015). Os trabalhadores dos boxes do Mercado de Peixe do Ver-o-Peso são comumente chamados de "peixeiros", e estes costumam comprar o pescado no próprio complexo, denominado "pedra do Ver-o-Peso" (OLIVEIRA NETO et al., 2016).

A atividade de processamento de pescados é grande geradora de resíduos e efluentes, ocorrendo em maior quantidade em indústrias, porém, os mercados de comercialização de pescados também realizam filetagem e outros tipos de cortes que geram resíduos, além de lavagem dos peixes, utensílios e instalações, produzindo uma quantidade considerável de efluentes. (LEITE et al., 2016; GUIMARÃES et al., 2018). Os resíduos orgânicos de origem biológica tornamse fontes poluentes durante o processo de decomposição, com desenvolvimento de micro-organismos causadores de doenças (ALMEIDA et al., 2013).

O objetivo deste trabalho foi realizar um levantamento da geração e destinação dos resíduos de peixes gerados no Mercado de Ferro do Ver-o-Peso, na cidade de Belém, Pará.

\section{MATERIAL E MÉTODOS}

\section{Caracterização da área de estudo}

A cidade de Belém está localizada ao nordeste do estado do Pará, sob as coordenadas geográficas $01^{\circ} 27^{\prime} 20^{\prime \prime}$ Latitude Sul e $48^{\circ} 30^{\prime} 15^{\prime \prime}$ Longitude Oeste (BELÉM, 2012). Belém é banhada pelo rio Guamá e pela baia de Guajará, e está distribuída em oito distritos administrativos, que englobam 71 bairros e 39 ilhas em uma área de 1.059,458 km² (BELÉM, 2018a; IBGE, 2018).

Belém apresenta a economia baseada principalmente nas atividades de comércio e serviços e uma população estimada em 1.452.275 habitantes, para o ano de 2017 (BELÉM, 2018a; IBGE, 2018). Apresenta clima quente e úmido com precipitação média anual de $2.834 \mathrm{~mm}$; a temperatura média é de $25^{\circ} \mathrm{C}$ a 26 ${ }^{\circ} \mathrm{C}$, localizada na zona climática Afi (classificação de Köppen) (BELÉM, 2012). A cidade de Belém possui 35 feiras e 20 mercados de onde são recolhidos 140 toneladas de lixo diariamente, com predominância de matéria orgânica (BELÉM, 2018b). A prefeitura do município realiza coleta de lixo diariamente, lavagem geral mensal das instalações dos mercados e controle de roedores, por meio da Secretaria Municipal de Saneamento (SESAN) na capital e distritos (BELÉM, 2018b).

O Mercado de Ferro, localizado no Complexo do Ver-oPeso, na cidade de Belém, conforme indica a Figura 1, apresenta-se dividido em 60 boxes de comercialização de peixes, com aproximadamente $9,4 \mathrm{~m}^{2}$ cada, sendo separados por divisórias de alvenaria (ALVES et al., 2017).

\section{Coleta de dados}

A coleta de dados foi realizada em dois momentos, em outubro e novembro de 2015 e em julho de 2018, sendo os dias escolhidos inteiramente ao acaso, os dados coletados consistiram em informações referentes aos resíduos de peixes por meio de formulários aos vendedores do interior do Mercado de Ferro; separação e pesagens dos resíduos de peixe gerados no interior do mercado, com o objetivo de quantificar os resíduos, identificando o tipo mais recorrente.

Entre os anos 2010 e 2015, o Mercado de Peixe do Ver-oPeso passou por intervenções devido às obras de restauração e conservação, pois o Mercado é um edifício histórico, e as 
mudanças ocorridas após a reforma consistiram principalmente em recuperação e/ou substituição de seus elementos estruturais, a fim de conservar as características arquitetônicas do Mercado
(CRUZ, 2015). As pesquisas foram realizadas logo após a reforma (2015) e três anos após a reforma, no ano de 2018.

Figura 1. Mapa de localização do Mercado de Ferro do Complexo do Ver-o-Peso na cidade de Belém Pará

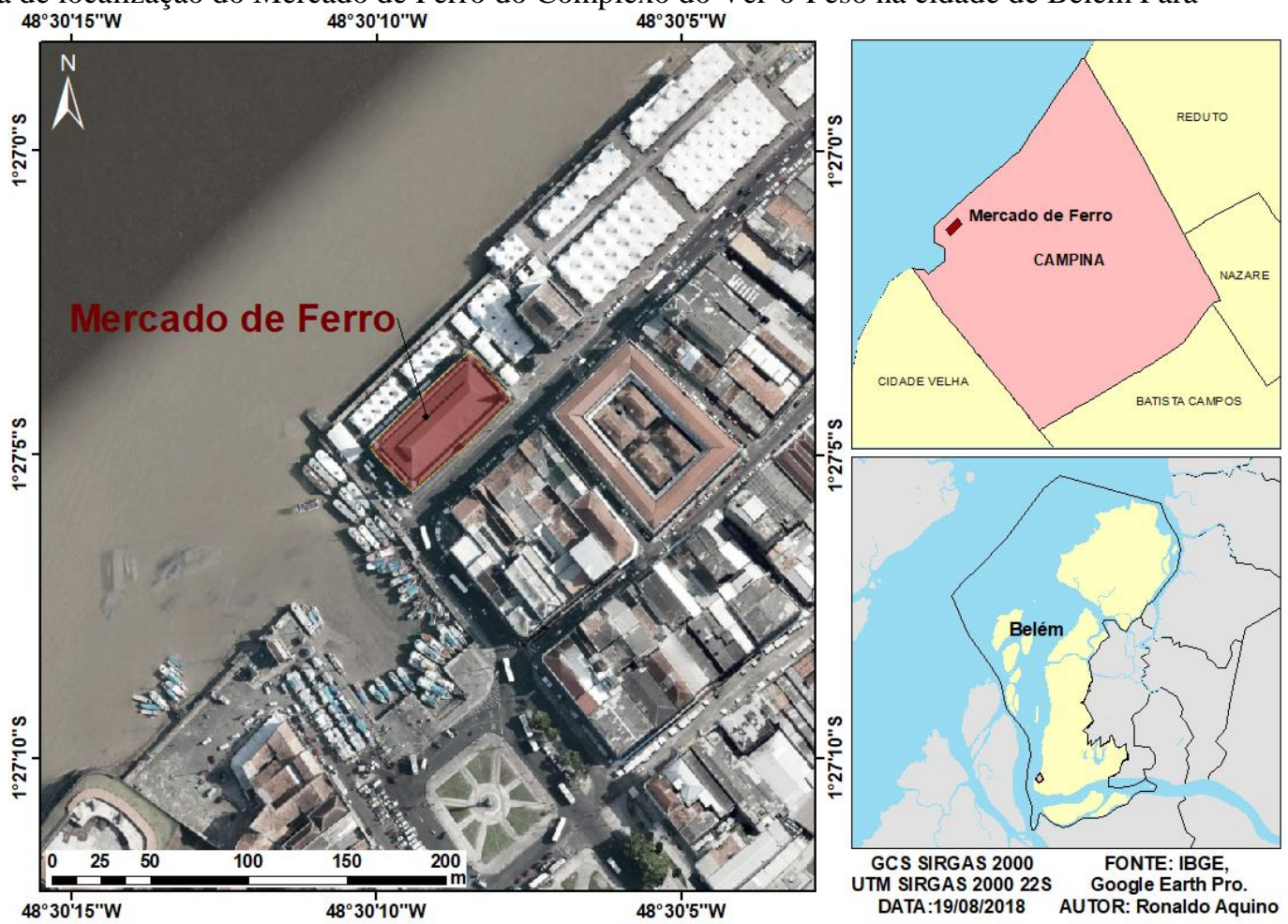

Os formulários foram aplicados em todos os boxes, exceto para os vendedores ausentes ou que não consentiram em participar, todos assinaram o termo de consentimento livre e esclarecido. Os formulários apresentaram perguntas referentes ao tipo de processamento que realizavam no pescado, espécies mais comercializadas, espécies que mais geram resíduos, tipos de resíduos e subprodutos. Foram feitas observações diretas, entrevistas e registro fotográfico para obtenção de informações adicionais. Para a identificação dos boxes, os formulários foram aplicados utilizando como identificação as numerações presentes em cada boxe do mercado, pois os 60 boxes apresentam numerações individuais.

O mercado é dividido em dois corredores, cada um formado por 30 boxes, cada corredor apresenta um container para despejo dos resíduos, de onde foram coletados, separados e pesados. No ano de 2015 as pesagens foram realizadas em um único container e em 2018 em dois containers. A pesquisa consistiu em realizar o acompanhamento do início ao fim de um dia de trabalho para contabilizar a produção de resíduos, consistindo em separação e pesagem dos resíduos de peixes por tipo.

Primeiramente, os resíduos de peixes foram separados por tipo por meio da observação visual: Tipo 1: pele; tipo 2: Carcaça (cabeça + espinhaço) e tipo 3: outros (nadadeiras, peixes inteiros impróprios para a comercialização, bexiga natatória - grude, brânquias e escamas) e pesados separadamente em quilogramas. Dependendo da espécie de peixe, o grude apresenta alto valor comercial e de exportação para países asiáticos e europeus.

Foram realizadas três pesagens dos resíduos de peixes, duas em 2015 (dois quadrantes) e uma em 2018 (quatro quadrantes). Para as pesagens, foi utilizada uma balança digital disponível no Mercado de Peixe do Ver-o-Peso, com capacidade para 200 quilogramas, onde os resíduos foram pesados em uma caixa vazada tipo monobloco a qual pesava 2,0 $\mathrm{kg}$ (em 2015) e 1,9 kg (em 2018). Os dados quantitativos e qualitativos foram organizados em planilhas do programa computacional Microsoft Office Excel, sendo utilizada a estatística descritiva para a análise dos dados.

\section{RESULTADOS E DISCUSSÃO}

Ao realizar a soma de todos os resíduos de peixes pesados em um dia de vendas no Mercado de Ferro no ano de 2018, independentemente da categoria, obteve-se 1.845,65 kg (Figura 2), porém, se o valor obtido no Mercado de Ferro em Belém, fosse estimado para um mês, ultrapassaria o valor calculado para os dois principais mercados da cidade de Santos, em São Paulo, caracterizado por Leite et al. (2016), que identificaram uma quantidade aproximada de 20 toneladas de resíduos de pescados descartados por mês nos dois centros de comercialização. Os resultados das pesagens realizados no Mercado do Ver-o-Peso demonstram a grande geração de resíduos em um único mercado de venda de peixes, sem incluir outros mercados e feiras livres na cidade de Belém, Pará. 
Figura 2. Pesagens de resíduos de peixes no Mercado do Ver-o-Peso, Belém, Pará

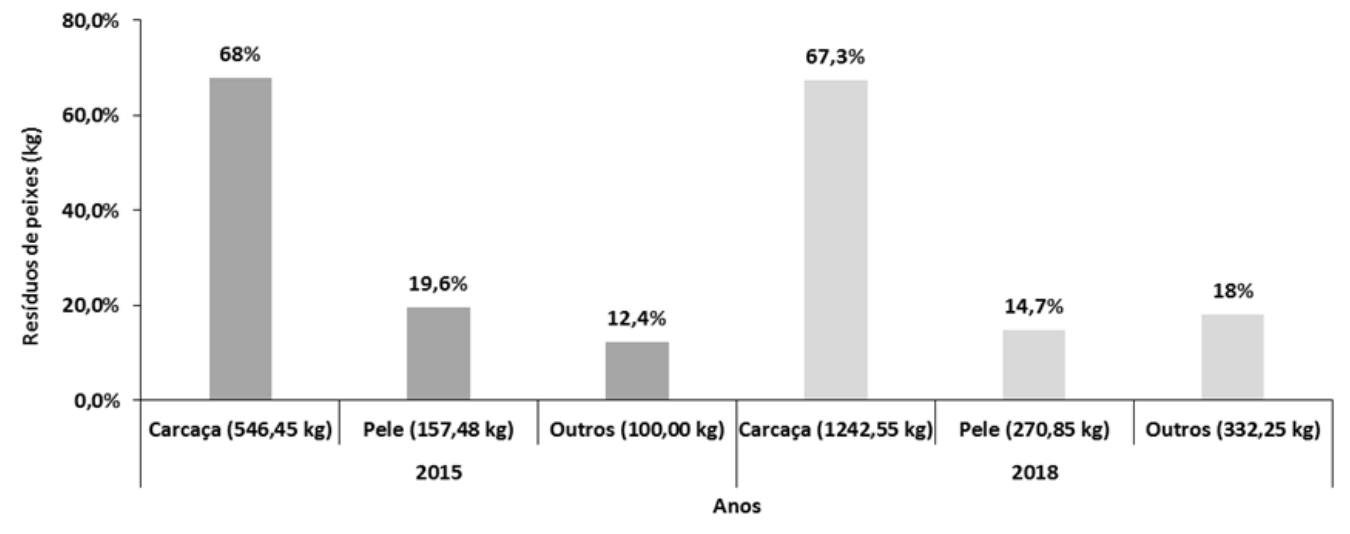

Para os anos de 2015 e 2018, a carcaça apresentou o maior valor, representando $68 \%$ para o ano de 2015 e $67,3 \%$ para o ano de 2018 (Figura 2). Considerando que a carcaça é o resíduo oriundo da filetagem, Lopes et al. (2016) afirmaram haver uma preferência por parte da população brasileira no consumo de filés, sobressaindo o filé fresco, quando comparado ao filé congelado.

As encomendas de filés de peixes para restaurantes locais também contribuem para o aumento do volume de carcaças presentes no Mercado, sendo que a quantidade de resíduos coletada poderá ser estimada para períodos mensais ou anuais, sendo possível, a partir de dados reais, conhecer os resíduos de pescados gerados, sua real destinação, propor melhorias para destinação de resíduos, além de estimar a quantidade média de pescado comercializada em determinado ponto de vendas.

A considerável quantidade de carcaças de peixes pode sugerir uma preferência por consumo de pescado filetado na cidade de Belém. De acordo com Costa e Souza (2012), há uma exigência do cliente para retirar todas as partes não utilizáveis no momento da compra, essas práticas também ocorrem no mercado da cidade de Belém, onde satisfazer a vontade do cliente, pode garantir o seu retorno ao mesmo vendedor, diferentemente de Greggio et al. (2018), onde, nem todos os balcões do Mercado de peixes, da cidade italiana Rimini, fornecem este tipo de serviço.

As demais categorias (pele e outros) apresentaram-se baixas, entre $12,4 \%$ e 19,6\%, em ambos os anos (Figura 2). A categoria "outros" engloba nadadeiras, escamas, brânquias, e grude, que geralmente são retirados no momento de comercialização do pescado inteiro ou processado. São poucos os pescados que chegam ao mercado com o grude, devido a sua importância comercial, principalmente das espécies pescada amarela, Cynoscion acoupa (Lacepède, 1802) e gurijuba, Sciades parkeri Traill, 1832 que apresentam o grude de maior valor comercial, com o preço do quilo do grude seco mais elevado quando comparado ao quilo da carne do pescado (MATOS; LUCENA, 2006; PALHETA; SILVA, 2011).

Também não foram encontrados intestinos, pois os peixes costumam ser eviscerados ainda na embarcação, logo após a captura para inibir processos enzimáticos e microbiológicos. Eviscerar os peixes a bordo e descartar as vísceras no mar é uma prática comum, sendo que a água do descongelamento do gelo que conserva o pescado na embarcação, contendo resíduos e sangue do pescado, podem ser contaminantes devido à quantidade de matéria orgânica presentes nos efluentes despejados no ambiente aquático (ARCHER et al., 2001; ALBERT et al., 2014). Ainda, de acordo com Albert et al. (2014), em pequenas e médias embarcações da pesca artesanal, os porões de armazenamento de pescado são lavados, descarregando entre 570 e $680 \mathrm{~L}$ de efluentes por dia. Baseado nisso, os despejos de resíduos e efluentes ocorre desde o momento da captura, não se restringindo aos mercados, feiras e indústrias, durante o processamento e/ou comercialização.

Assim como existe um período em que as vendas de peixes aumentam no estado do Pará, a exemplo da Semana Santa, com popular tradição no consumo de carne de pescado, havendo um decreto estadual que proíbe a exportação de peixe fresco e resfriado para outros Estados, também há um período do ano em que as vendas de peixes diminuem (ADEPARÁ, 2017). Greggio et al. (2018) estimaram haver uma produção média mensal de 1,34 toneladas de resíduos de peixes em uma região italiana, oriundas de mercados de comercialização de peixes, com exceção do mês de agosto, quando a pesca para temporariamente. A estimativa foi baseada em dados da Secretaria do Mercado de Peixes da cidade, escolhida por ser bastante representativa em processamento de peixes, além de aplicação de questionários aos fornecedores, sendo os dados, extrapolados para os demais mercados regionais.

De acordo com os comerciantes de peixes, um dos meses em que os resíduos foram pesados, julho de 2018, correspondeu a um período de menor fluxo de comercialização de pescado, pois, apesar de ser um dos dias da semana de maior venda de filés para os restaurantes, é também o mês de férias escolares, período no qual há uma migração da população para os municípios do interior do Estado, e o consumo de peixes consequentemente aumenta nos municípios de veraneio e diminui na cidade de Belém.

Para os anos de 2015 e 2018, 46,4\% e 41,2\% dos comerciantes de peixes do Mercado do Ver-o-Peso afirmaram, respectivamente, que os peixes filetados são os maiores geradores de resíduos, pois, na maioria das vezes, metade do pescado é desperdiçada durante o processamento (Figura 3). De acordo com Fraslin et al. (2018), trabalhos adicionais vêm sendo realizados com o intuito de aumentar o rendimento de filés de peixes. 
Figura 3. Tipos de pescados que mais geram resíduos no Mercado do Ver-o-Peso, Belém, Pará

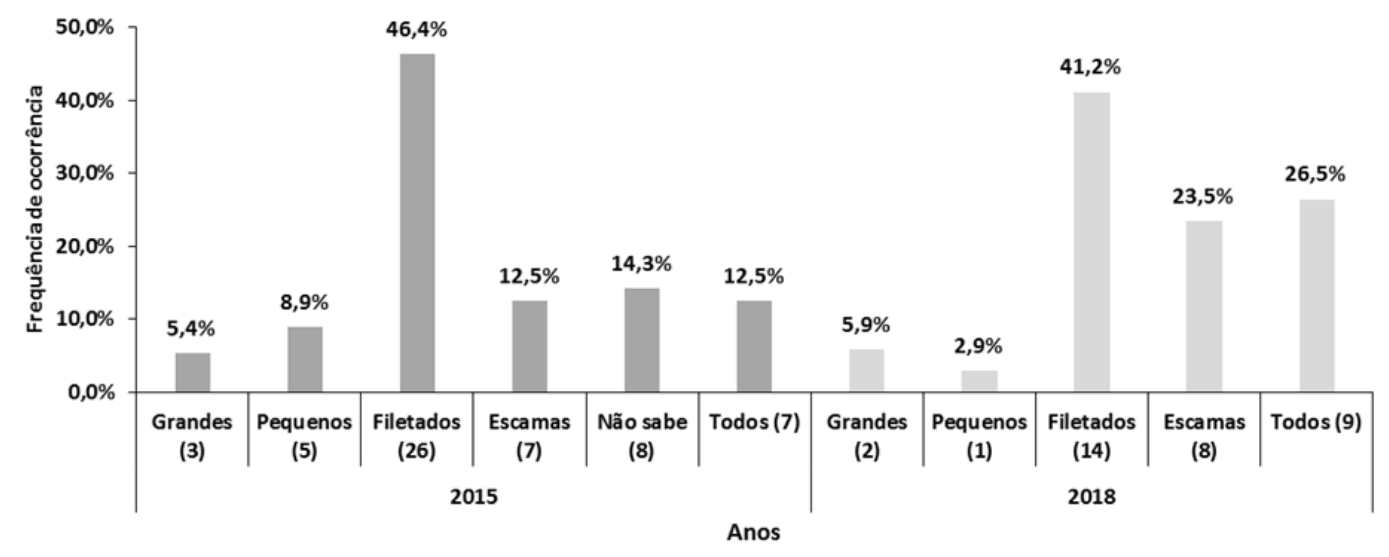

Dos comerciantes, $12,5 \%$ e $23,5 \%$ acreditam que os peixes de escamas são geradores de resíduos, porque além do volume que essas escamas representam, apresentam a pele mais espessa quando comparado aos peixes sem escamas (Figura 3). De acordo com Costa e Souza (2012), os peixes com escamas apresentam um processamento mais demorado, sendo retiradas as aparas, descamados, cortados e lavados.

Para os anos de 2015 e $2018,5,4 \%$ e $5,9 \%$ dos comerciantes, respectivamente, afirmaram que os peixes maiores geram mais resíduos, devido ao fato de que a região anterior do corpo é bem maior, havendo mais perdas. Os dados corroboram com Vandeputte et al. (2017) ao afirmarem que o tamanho da cabeça tem efeitos opostos nos rendimentos de carcaça e de filé. Dos comerciantes, 8,9\% (2015) e 2,9\% (2018) responderam que os peixes pequenos geram mais resíduos, pois, geralmente, apresentam um menor prazo de prateleira, deteriorando-se mais rapidamente, sendo denominados popularmente de "peixes fracos". Costa e Souza (2012) identificaram em suas pesquisas o curto prazo que um peixe apresenta ao ficar exposto, pois caso não seja vendido, dura menos de dois dias, e após esse período, realiza-se o descarte.
Em relação ao percentual, 12,5\% e 26,5\%, em 2015 e 2018, acreditam não haver diferenças na geração de resíduos em função do tipo de processamento ou características do pescado. Em 2015, 55,3\% e em 2018, 32,4\% dos vendedores de pescado afirmaram que produzem até $50 \mathrm{~kg}$ de resíduos por dia em seus boxes; seguido de $17,9 \%$ (2015) e $17,6 \%$ (2018) que informaram produzir entre 50 a $100 \mathrm{~kg}$ de resíduos; $17,9 \%$ (2015) e $23,5 \%$ (2018) produzem entre 100 e $200 \mathrm{~kg} ; 7,1 \%$ (2015) e 5,9\% (2018) produzem acima de $200 \mathrm{~kg}$ por dia; $1,8 \%$ (2015) 20,6\% (2018) não souberam responder (Figura 4).

Scherhaufer et al. (2018) relataram os impactos do desperdício de alimentos, incluindo os peixes brancos, confirmando que os alimentos de origem animal se caracterizam como os maiores geradores de impactos. Os autores consideraram desperdício como qualquer parte comestível ou não comestível de alimentos removidos da cadeia de fornecimento e enviados para tratamento e deposição de resíduos, desconsiderando as doações ou destinação para alimentação animal.

Figura 4. Resíduos gerados por boxe $(\mathrm{kg})$ estimados pelos comerciantes de peixe do Ver-o-Peso, Belém, Pará

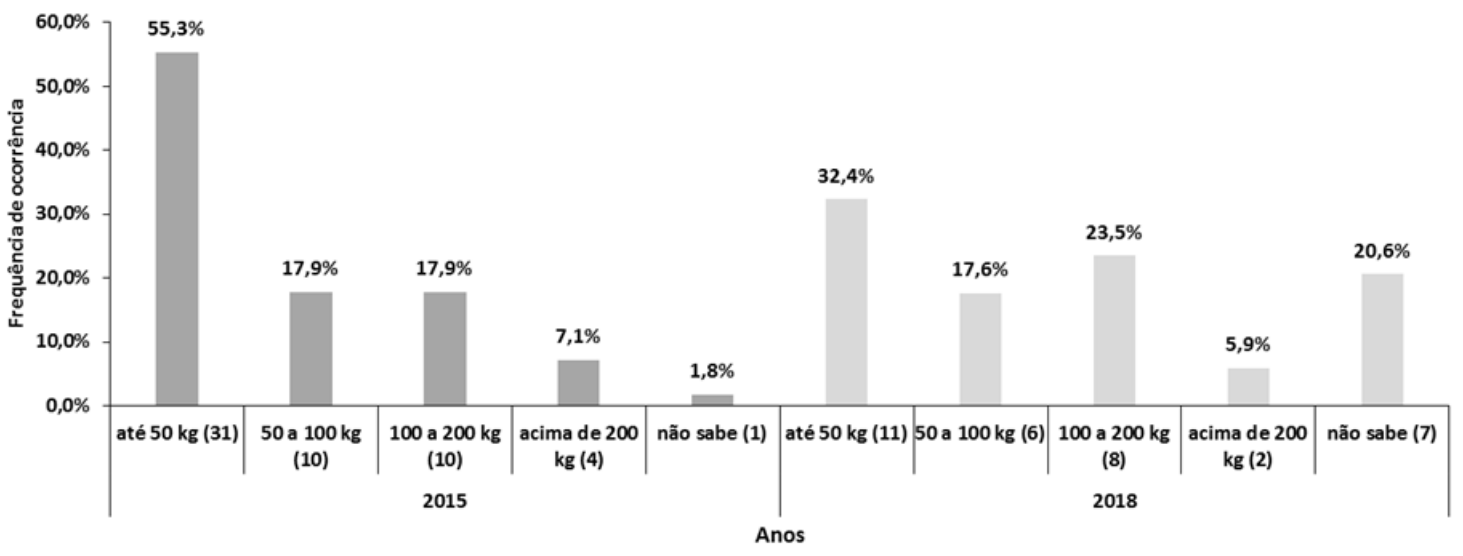

Nos anos de 2015 e 2018, 67,9\% e 44,1\%, respectivamente, responderam que os resíduos são despejados no lixo, com destino ao aterro sanitário, sendo transportados durante a coleta de lixo urbano, corroborando com Leite et al.
(2016) ao afirmarem que 100\% dos resíduos de dois centros de comercialização de pescado de São Paulo são destinados ao aterro sanitário da cidade. Abdel-Shafy e Mansour (2018) enfatizaram que os locais de descarte de resíduos sólidos 
urbanos mais utilizados, por serem mais baratos, são os aterros sanitários (Figura 5).

Entre os anos de 2015 e 2018, ocorria uma transição, pois o lixo doméstico ainda era despejado em lixão a céu aberto, conhecido como Lixão do Aurá, no município de Ananindeua, Pará, e posteriormente foi construído um aterro sanitário no município de Marituba, Pará, ambos na Região Metropolitana de Belém.

Para os anos de 2015 e $2018,21,4 \%$ e $35,3 \%$ dos comerciantes afirmaram que o destino dos resíduos é o descarte no lixo e doação. Para o primeiro ano, a doação consistia em pessoas que pediam cabeças de peixes para utilizarem na própria alimentação. No segundo ano, as doações foram feitas para uma indústria de reciclagem de resíduos de origem animal, para elaboração de farinha de peixe. Apesar da grande quantidade de resíduos gerados, não se observou no local, despejo inadequado, nas ruas ou no ambiente aquático que margeia o Complexo do Ver-o-Peso, sendo os resíduos de peixes descartados em containers (Figura 5). Wang et al. (2018) acreditam que a presença de qualquer local de deposição organizada de lixo incentiva fortemente o comportamento de descarte adequado.

Figura 5. Destino dos resíduos de pescado do Mercado de Ferro do Complexo do Ver-o-Peso, Belém, Pará

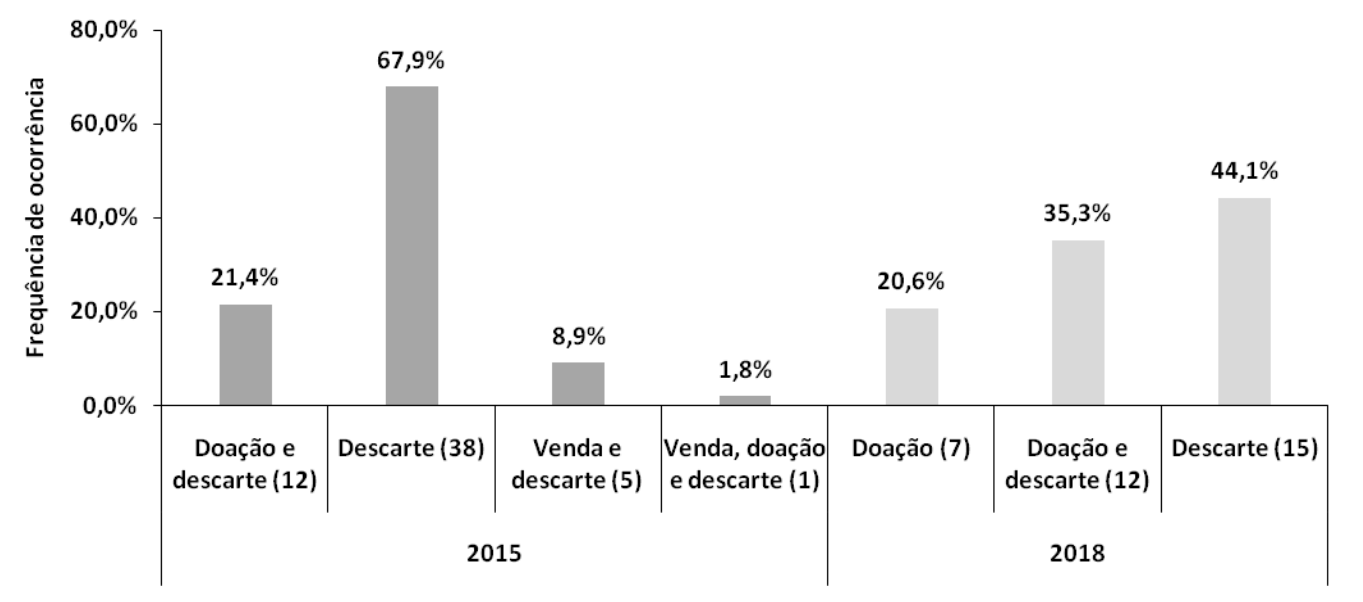

No ano de 2015, 8,9\% dos comerciantes de peixe do Vero-Peso, responderam vender e descartar os resíduos, e 1,8\% vendiam, doavam e descartavam os resíduos no lixo, como destino final. Geralmente, as doações e comercializações de resíduos, consistem em cabeças e carcaças de peixes, oriundos do processo de filetagem, apresentando uma significativa quantidade de resíduo cárneo. Alguns comerciantes expõem as cabeças de peixes nos balcões de vendas, sendo bastante utilizadas no preparo de caldos de peixe. Para o ano de 2018, 20,6\% dos entrevistados afirmaram doar os resíduos (Figura 5).

Foram constatadas diferenças no destino dos resíduos do ano de 2015 para 2018, sendo que no primeiro ano a maior parte dos resíduos era destinada ao aterro sanitário. No ano de 2018, grande parte dos resíduos foi reaproveitada para produção de farinha de peixe, porém, isso é realizado por uma única empresa privada, que ainda não consegue transportar os resíduos em sua totalidade.

Em ambos os anos (2015 e 2018), de acordo com os comerciantes, o tipo de resíduo de pescado mais comum de ser encontrado nos boxes de comercialização de peixes foi a carcaça (32,1\% em 2015 e 50\% em 2018), contudo, a separação por tipo e pesagem dos resíduos, realizadas no local, também o comprovaram. A segunda categoria mais recorrente no ano de $2015(28,6 \%)$ foi "pele e outros", a segunda categoria mais recorrente para o ano de $2018(32,4 \%)$ foi a categoria "outros". As demais categorias mantiveram-se entre $2,9 \%$ e $16,1 \%$, sendo que no ano de 2015, 1,8\% dos entrevistados responderam não haver diferença na composição dos resíduos (categoria "todos"), de acordo com a Figura 6.
Figura 6. Tipos de resíduos de pescado mais encontrados no Mercado de Ferro do Complexo do Ver-o-Peso, Belém, Pará

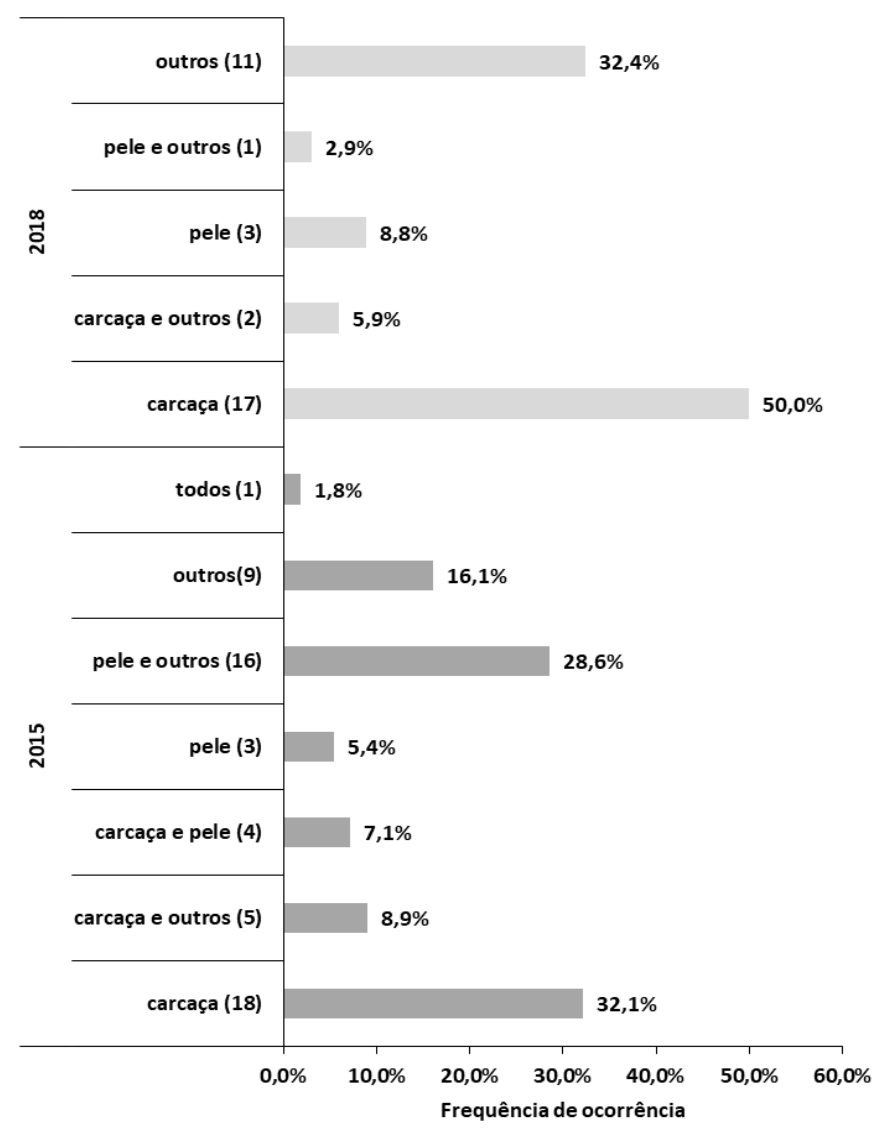


Diferentemente de Costa e Souza (2012), ao relatarem que metade dos entrevistados não conheciam o valor comercial dos resíduos, nesta pesquisa, os entrevistados, de forma geral, conheciam mais de uma possibilidade de aproveitamento de resíduos de peixes, como mostra a Figura 7.

Em ambos os anos, 2015 e 2018, 66,1\% e 79,4\% dos comerciantes entrevistados apresentaram conhecimentos referentes ao uso de resíduos de peixes para a produção de adubo, ração e para a alimentação humana. Nnali e Oke (2013) utilizaram no solo, antes da lavoura, biofertilizante oriundo do pescado com a água de irrigação, para reduzir moscas e odor desagradável. Dou et al. (2018) acreditam que a utilização dos resíduos de alimentos para a alimentação animal é uma solução viável que aborda a gestão de resíduos, segurança alimentar, conservação de recursos e prevenção da poluição. Amaral et al. (2017) descreveram técnicas artesanais de beneficiamento do Hypophthalmus edentatus Spix, 1829, o "mapará", para o aproveitamento dos resíduos, elaborando filés marinados, empanados, hambúrguer, almôndega, defumados, embutidos, bolinho, nuggets, patê, apresuntado e biscoito.

Quando os comerciantes se reportaram sobre alimentação humana, se referiram principalmente a caldos de peixe com as carcaças, existem muitas alternativas de produtos viáveis a serem elaborados a partir desses resíduos, porém, Wong et al. (2016) relataram a atual problemática da contaminação de peixes por metais pesados, especialmente os peixes de ambientes naturais, quando comparados com os oriundos da piscicultura. Os autores enfatizam o risco de existir contaminação em rações para peixes, devido à farinha e ao óleo de peixes contaminados, que são os principais ingredientes de ração para organismos aquáticos da aquicultura, geralmente produzidos com resíduos de peixes, isso demonstra que os resíduos devem ser seguros ao consumo humano e animal, reforçando a importância da segurança alimentar.

Figura 7. Produtos que poderiam ser gerados com os de resíduos de pescado, no Mercado de Ferro do Complexo do Ver-o-Peso, Belém, Pará

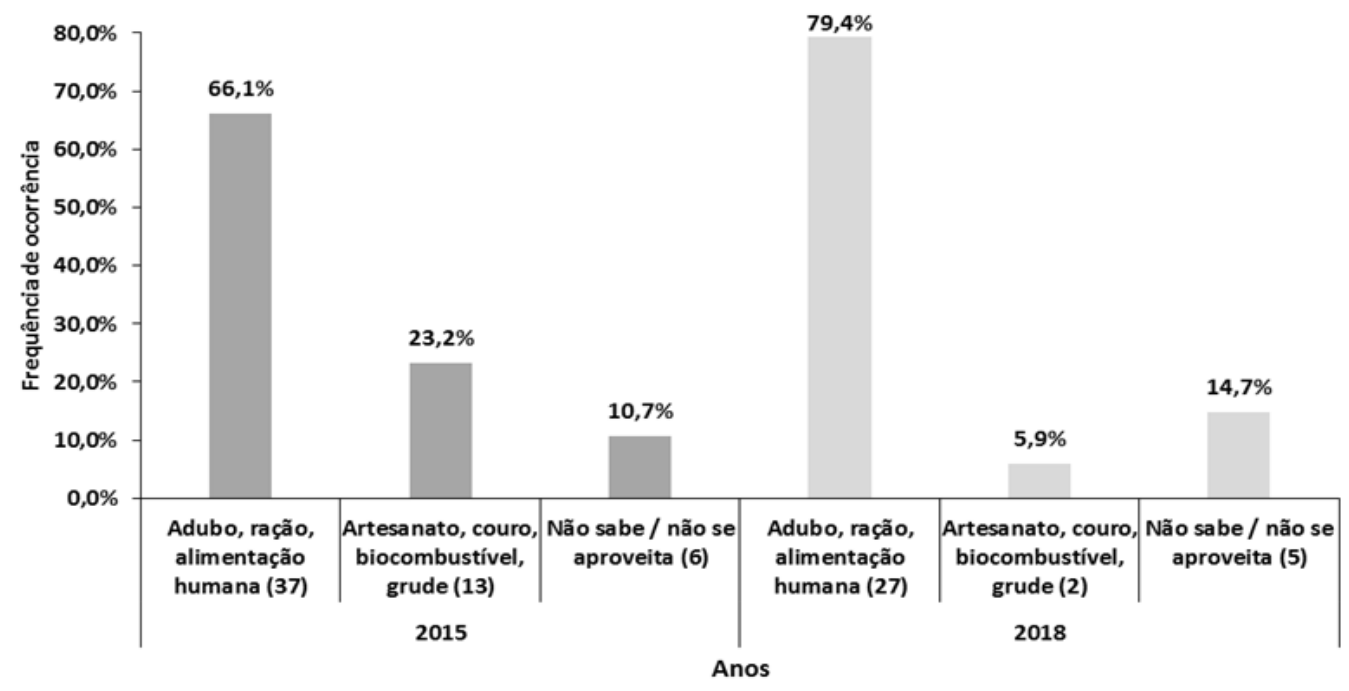

Os demais comerciantes, para os anos de $2015(23,2 \%)$ e $2018(5,9 \%)$, acreditavam que os resíduos poderiam ser utilizados para fins artesanais, curtimento do couro, comercialização do grude e também se mostraram conhecedores da possibilidade de se produzir biocombustível com os resíduos (Figura 7). Costa et al. (2016) realizaram cursos de capacitação em artesanato com escamas de peixe em uma comunidade de pescadores no estado de Pernambuco, com o objetivo de contribuir com a melhoria da renda familiar, com o fortalecimento da cadeia produtiva da pesca artesanal e com a preservação do meio ambiente. Na Figura 7, em 2015 (10,7\%) e em $2018(14,7 \%)$ dos comerciantes de peixes não souberam responder ou não apresentavam conhecimentos referentes a esta temática, acreditando não poder ter outra destinação, se não, o descarte total dos resíduos de peixes.

Partindo do princípio de que a estatística pesqueira se encontra em defasagem no Brasil, os dados coletados nos mercados, feiras e supermercados poderiam contribuir parcialmente com estimativas pesqueiras, sugerindo-se outros estudos nos demais mercados e feiras livres do Brasil, com coleta, pesagem e separação dos resíduos.

\section{CONCLUSÕES}

No Mercado de Ferro do Complexo do Ver-o-Peso, os resíduos mais frequentes são carcaças oriundas da filetagem, sendo a atividade de processamento mais realizada, havendo uma preferência por parte da população. A quantificação desses resíduos atinge um total superior a uma tonelada e meia por dia. A destinação dos resíduos de peixes oriunda do mercado consiste principalmente em descarte e doação, sendo que o descarte é realizado no mesmo ambiente do lixo doméstico, o aterro sanitário.

\section{REFERÊNCIAS}

ABDEL-SHAFY, H. I.; MANSOUR, M. S. M. Solid waste issue: Sources, composition, disposal, recycling, and valorization. Egyptian Journal of Petroleum, v.27, n.4. p.12751290, 2018. 10.1016/j.ejpe.2018.07.003 
ADEPARÁ. Agência de defensa agropecuária do estado do Pará - ADEPARÁ. 2017. Adepará reforçará fiscalização da saída do pescado durante a Semana Santa. 2017. Disponível em: <http://www.adepara.pa.gov.br/artigos/adepará-reforçaráfiscalização-da-saída-do-pescado-durante-semana-santa> . Acesso em: 24 Set. 2018.

ALBERT, R. J.; MCLAUGHLIN, C.; FALATKO, D. Characterization of fish hold effluent discharged from comercial fishing vessels into harbor waters. Marine Pollution Bulletin, v.87, n.1, p.29-38, 2014. 10.1016/j.marpolbul.2014.08.

ALMEIDA, R. N.; BITENCOURT, D. V.; PEDROTTI, A.; SANTOS, L. C. P. A problemática dos resíduos sólidos urbanos. Interfaces Científicas - Saúde e Ambiente, v. 2, n. 1, p. 25-36, 2013.

ALVES, E. M. P.; SILVA, A.; SOUSA, C. L.; FIGUEIREDO, H. M.; NEVES, E. A. Aspectos higiênicos-sanitários das instalações do mercado Ver-o-Peso e avaliação da temperatura dos peixes comercializados. Revista Ciência e Desenvolvimento, v.10, n.2, p.25-43, 2017.

AMARAL, M. T.; APARÍCIO, G. K. S.; SOUZA, P. L.; SANTOS, A. M. L. Aplicação de tecnologias tradicionais no beneficiamento do pescado na região do baixo amazonas, estado do Pará. Revista Gestão, Inovação e Tecnologias, v.7, n.1, p.3708-3721, 2017. 10.7198/geintec.v7i1.840.

ARCHER, M.; WATSON, R.; DENTON, J. W. Fish waste production in the United Kingdom: The quantities produced and opportunities for better utilisation. Seafish Report, n.SR537, 2001. 57p.

BARTHEM, R. B. O desembarque na região de Belém e a pesca na foz amazônica. In: Ruffino, M. L. A pesca e os recursos pesqueiros na Amazônia brasileira. Manaus: Ibama/ProVárzea, 2004. 272p.

BELÉM. Anuário Estatístico do Município de Belém, v. 16, 2011 - Belém: Secretaria Municipal de Coordenação Geral do Planejamento e Gestão, 2012. 411 p.

BELÉM. Prefeitura Municipal de Belém. História de Belém PA. Belém-tur. Disponível em: <http://www.belem.pa.gov.br/belemtur/site/?page_id=459> Acesso em: 06 Jul. 2018a.

BELÉM. Prefeitura Municipal de Belém. Secretaria Municipal de Saneamento (SESAN). Limpeza: Feiras de Belém contam com coleta diária de lixo e lavagem programada. 2018. Disponível em: <http://agenciabelem.com.br/Noticia/170585/feiras-de-belemcontam-com-coleta-diaria-de-lixo-e-lavagem-programada>. Acesso em: 15 Jul. 2018b.

BRASIL. Lei $\mathrm{n}^{\mathrm{o}}$ 12.305, de 2 de agosto de 2010. Institui a Política Nacional de Resíduos Sólidos; altera a Lei no 9.605, de
12 de fevereiro de 1998; e dá outras providências. Disponível em: <http://www.planalto.gov.br/ccivil_03/_ato20072010/2010/lei/112305.htm>. Acesso em: 14 Jul. 2018.

BRASIL. Ministério da Pesca e Aquicultura (MPA). Relatório referente à coleta dos dados da produção de pesca e aquicultura realizada pela Secretaria - Executiva do Ministério da Pesca e Aquicultura. 2014.

COSTA, S. R.; SOUZA, P. A. R. O impacto dos resíduos de pescado: O caso da "Feira do Bagaço" no município de Parintins no Amazonas. Revista DELOS, v.5, n.14, 2012.

COSTA, W. M.; VEIGA, J. M. A. V.; MOURÃO, M. C.; RODRIGUES, J. M.; SANTOS, J. F. Aproveitamento de resíduos de pescado: o artesanato com escamas de peixe. Revista Ciência em Extensão, v.12, n.2, p.8-17, 2016.

CRUZ, C. F.; MESQUITA, F. J.; SARQUIS, G. B. Mercado de Ferro : restauração e conservação 2010/2015. - Belém, PA: Iphan-PA, 2015. 18p.

DOU, Z.; TOTH, J. D.; WESTENDORF, M. L. Food waste for livestock feeding: Feasibility, safety, and sustainability implications. Global Food Security, v.17, n.1, p.154-161, 2018. 10.1016/j.gfs.2017.12.003.

Food and Agriculture Organization of the United Nations FAO. The State of World Fisheries and Aquaculture: Meeting the sustainable development goals. Rome: FAO, 2018. 227p.

FRASLIN, C.; DUPONT-NIVET, M.; HAFFRAY, P.; BESTIN, A.; VANDEPUTTE, M. How to genetically increase fillet yield in fish: New insights from simulations based on field data. Aquaculture, v.486, n.3, p.175-183, 2018. 10.1016/j.aquaculture.2017.12.012.

GREGGIO, N.; CARLINI, C.; CONTIN, A.; SOLDANO, M.; MARAZZA, D. Exploitable fish waste and stranded beach debris in the Emilia-Romagna Region (Italy). Waste Management, v.78, n.1, p.566-575, 2018. 10.1016/j.wasman.2018.06.034.

GUIMARÃES, J. T.; SOUZAA, A. L. M.; BRÍGIDA, A. I. S.; FURTADO, A. A. L.; CHICRALA, P. C. M. S.; SANTOS, V. R. V.; ALVES, R. R.; LUIZ, D. B.; MESQUITA, E. F. M. Quantification and characterization of effluents from the seafood processing industry aiming at water reuse: A pilot study. Journal of Water Process Engineering, v.26, p.138-145, 2018.

HOORNWEG, D.; BHADA-TATA, P. What a Waste: A Global Review of Solid Waste Management. Washington: World Bank, 2012. 116p.

Instituto Brasileiro de Geografia e Estatística (IBGE). População. Disponível em: <https://www.ibge.gov.br/estatisticas-novoportal/por- 
cidade-estado-estatisticas.html? $\mathrm{t}=$ destaques $\& \mathrm{c}=1501402>$.

Acesso em: 15 Jul. 2018.

Instituto do Patrimônio Histórico e Artístico Nacional (IPHANPA). Revitalização da feira do Ver-o-Peso Projeto básico. Disponível $<$ http://portal.iphan.gov.br/uploads/ckfinder/arquivos/1 \%20Ve r-o-Peso\%20-\%20APRESENTACÃO\%20R01.pdf>. Acesso em: 22 Jul. 2018.

LEITE, S. B. P.; SUCASAS, L. F. A.; OETTERER, M. Resíduos da comercialização de pescado marinho - volume de descarte e aspectos microbiológicos. Revista Brasileira de Tecnologia Agroindustrial, v.10, n.1, p.2112-2125, 2016.

LOPES, I. G.; OLIVEIRA, R. G.; RAMOS, F. M. Perfil do consumo de peixes pela população brasileira. Biota Amazônia, v.6, n.2, p.62-65, 2016. 10.18561/21795746/biotaamazonia.v6n2p62-65.

MATOS, I. P.; LUCENA, F. Descrição da pesca da pescadaamarela, Cynoscionacoupa, da costa do Pará. Arquivos de Ciências do Mar, v.39, n.1, p.66-73, 2006.

NNALI, K. E.; OKE, A. O. The utilization of fish and fish farm wastes in biogas production: "a review". The utilization of fish and fish farm wastes in biogas production: "a review". Advances in Agriculture, Sciences and Engineering Research, v.3, n.1, p.656-667, 2013.

OLIVEIRA NETO, A.; DINIZ, J. D. A.; LEITÃO, W. M.; SAMPAIO, D. S. Coordenação do Comércio Atacadista de Pescado no Mercado do Ver-o-Peso, em Belém-Pará. Revista de Economia e Sociologia Rural, v.54, n.3, p.483-496, 2016.

PALHETA, J. M.; SILVA, C. N. Pesca e territorialidades: contribuições para análise espacial da atividade pesqueira. 1.ed. Belém: GAPTA/UFPA, 2011. 308p.

SCHERHAUFER, S.; MOATES, G.; HARTIKAINEN, H.; WALDRON, K.; OBERSTEINER, G. Environmental impacts of food waste in Europe. Waste Management, v.77, n.1, p.98113, 2018. 10.1016/j.wasman.2018.04.038.

SILVA, J. R.; COSTA, L. K. S.; SILVA, F. L. Técnicas de análise multivariada no agrupamento e classificação dos estados brasileiros segundo a produção pesqueira nacional. Observatorio de la Economía Latinoamericana, v.1, n.190, 2013. Disponível em: <http://www.eumed.net/cursecon/ecolat/br/13/pescanacional.hmtl>. Acesso em: 15 Jul. 2018.

SOUSA, E.; ALVES, R. J. M.; SILVA, J. M.; DIAS, N. M.; SILVA, L. C. Prospecção socioeconômica em feiras livres: o caso do Complexo do Ver-o-Peso, Belém, Pará, Brasil. Revista Espacios, v.38, n.36, 2017. Disponível em: <https://www.revistaespacios.com/a17v38n36/17383605.html $>$. Acesso em: 15 Jul. 2018.
VANDEPUTTE, M.; PULEDDA, A.; TYRAN, A. S.; BESTIN, A.; COULOMBET, C.; BAJEK, A.; BALDIT, G.; VERGNET, A.; ALLAL, F.; BUGEON, J.; HAFFRAY, P. Investigation of morphological predictors of fillet and carcass yield in European sea bass (Dicentrarchus labrax) for application in selective breeding. Aquaculture, v.470, n.1, p.40-49, 2017. 10.1016/j.aquaculture.2016.12.014.

WANG, F.; CHENG, Z.; REISNER, A.; LIU, Y. Compliance with household solid waste management in rural villages in developing countries. Journal of Cleaner Production, v.202, n.20, p.293-298, 2018. 10.1016/j.jclepro.2018.08.135.

WONG, M. H.; MO, W. Y.; CHOI, W. M.; CHENG, Z.; MAN, Y. B. Recycle food wastes into high quality fish feeds for safe and quality fish production. Environmental Pollution, v.219, n.1, p.631-638, 2016. 10.1016/j.envpol.2016.06.035 . 